\title{
РАЗРАБОТКА ТЕХНОЛОГИИ ПРИГОТОВЛЕНИЯ И ПРИМЕНЕНИЯ ГИСТОЛОГИЧЕСКИХ КРАСИТЕЛЕЙ НА ОСНОВЕ ЭКСТРАКТОВ БУЗИНЫ ЧЕРНОЙ, БАРХАТЦЕВ РАСПРОСТЕРТЫХ И ДОННИКА ЛЕКАРСТВЕННОГО*
}

\author{
(C) Т.А. Ииунина ${ }^{* *}$, С.Г. Боева \\ Курский государственный медицинский университет, ул. Карла Маркса, 3, \\ Курск, 305041 (Россия), e-mail: ishunina@gmail.com
}

\begin{abstract}
На основе спиртовых экстрактов плодов бузины черной (Sambucus nigra L.), цветков бархатцев распростертых (Tagetes patula L.) и донника лекарственного (Melilotus officinalis L.) получены новые гистологические красители. Антоцианы плодов бузины черной, имеющие в составе положительно заряженный кислород, обеспечивают основные свойства соответствующего красителя, который избирательно окрашивает ядра клеток и базофильные структуры цитоплазмы. В механизме окрашивания важную роль играют донорно-акцепторные связи, образующиеся между гетероциклическим атомом кислорода антоцианов и металлом-комплексообразователем (медь), входящим в состав медного купороса. Флавоноиды цветков бархатцев и донника, напротив, проявляют слабокислые свойства за счет наличия гидроксильных групп и преимущественно окрашивают цитоплазму и мембраны клеток. Механизм окрашивания заключается в образовании прочных комплексов между ионами железа и фенольными гидроксильными и карбонильными группами флавоноидов. В связи с этим новые красители следует считать протравными. К их преимуществам можно отнести доступность и широкое распространение растительного сырья, использование нетоксичных и недорогих ингредиентов, простоту приготовления растворов и возможность их длительного хранения и повторного использования. Более того, ядерный краситель на основе бузины черной может применяться для сочетанного гистологического окрашивания с цитоплазматическими красителями на основе цветков бархатцев и донника.

Ключевые слова: гистологические красители растительного происхождения, ядерные и цитоплазматические красители, плоды бузины черной, цветки бархатцев, цветки донника лекарственного, флавоноиды, антоцианы.
\end{abstract}

\section{Введение}

Методики гистологической окраски чаще всего основаны на комбинированном использовании двух красителей, один из которых, основной, окрашивает ядра и ядерные структуры клеток, а другой, кислотный, выявляет цитоплазматические структуры, эритроциты и отдельные компоненты межклеточного матрикса. Подавляющее большинство использующихся красителей - синтетического происхождения и импортного производства. Цена за 1 кг может составлять 28000 рублей (тионин, сафранин), 50 000-65 000 (гематоксилин, галлоцианин) и даже 1600000 рублей (крезиловый фиолетовый). Многие из них подходят для материала, зафиксированного только в специальных растворах, часть которых токсичны. Более того, методики с использованием таких красителей требуют кипячения, добавления токсичных материалов (формалин, соляная кислота) и длительного (до 24-48 ч) окрашивания. Единственный краситель растительного происхождения, гематоксилин, более прост с точки зрения приготовления и процедуры окраски. Но и у него есть ряд недостатков. Во-первых, гематоксилин получают из кампешевого дерева, которое

Ииунина Татьяна Александровна - кандидат медицинских наук, доцент кафедры гистологии, e-mail: ishunina@gmail.com

Боева Светлана Геннадьевна - студентка, e-mail: ishunina@gmail.com произрастает в Центральной Америке. Это означает некоторые ограничения в доступности этого импортируемого красителя. Во-вторых, после смешивания необходимых ингредиентов раствор должен созреть

\footnotetext{
* Данная статья имеет электронный дополнительный материал (приложение), который доступен читателям на сайте журнала. DOI: 10.14258/jcprm.2017021171s

Автор, с которым следует вести переписку.
} 
в процессе естественного окисления, которое длится от 7-10 дней до 2-3 недель [1]. Использовать такой краситель сразу же нельзя. Указанные недостатки имеющихся красителей поднимают вопрос о разработке более простых, дешевых и менее токсичных растворов. С учетом широкого представительства растений, содержащих красящие пигменты и использующихся в качестве красителей в пищевой и текстильной промышленности, целью наших исследований стала разработка новых гистологических красителей на основе доступного растительного сырья Центрально-Черноземного района. В настоящей работе изучались красильные свойства 1) плодов бузины черной (Sambucus nigra L.), 2) цветков донника лекарственного (Melilotus officinalis L.), повсеместно произрастающего в различных регионах Российской Федерации на лугах, пустырях, обочинах дорог, и 3) цветков бархатцев распростертых (Tagetes patula L.), широко культивируемых на приусадебных участках не только в декоративных целях, но и для защиты от вредителей, грибков и нематод. Эти растения нетоксичны, используются в пищевой и текстильной промышленности в качестве красителей, обладают лекарственными свойствами и применяются в медицине [2-11].

\section{Экспериментальная часть}

Для получения гистологических красителей спелые плоды бузины черной были собраны в начале сентября, цветки донника лекарственного - в первой половине июля, цветки бархатцев распростертых - во второй половине июля и августе на территории Курской области. Методика выделения красящих пигментов максимально проста и основана на статическом способе экстракции методом настаивания. Тип экстрагента, соотношение сырье : экстрагент и время настаивания были определены экспериментально. Для плодов, содержащих антоциановые пигменты, проверялись соотношения сырье : экстрагент $2: 1,1,8: 1$, $1,5: 1,1,25: 1,1: 1,1: 2$. Для экстрактов бузины наилучшие результаты окрашивания получены при соотношении $1,8: 1$ и $2: 1$. При соотношении $1,5: 1$ интенсивность окраски ядер клеток была намного ниже, что не позволяет рекомендовать соотношения с большим содержанием спирта. Для экстрактов цветков проверялись соотношения $1: 1,1: 1,5,1: 2,1: 2,5$ и $1: 3$. Интенсивность цвета экстрактов напрямую зависела от концентрации сырья. Тем не менее интенсивность окрашивания гистологических срезов при использовании соотношений от $1: 1$ до $1: 2$ практически не отличалась. Резкое снижение интенсивности окрашивания препаратов наблюдалось при соотношении $1: 3$. При этом важную роль играло время сбора сырья. У экстрактов цветков, собранных в начале цветения, красящие свойства были выражены в меньшей степени по сравнению с цветками в фазу массового цветения. Для экстрактов плодов, содержащих антоцианы, экспериментальные периоды настаивания составляли 4, 7, 10, 17, 20 дней, 2,5 месяца. Для экстрактов бузины наилучшие результаты получены при настаивании в течение 10-17 дней. При коротком экстрагировании (4 дня) интенсивность окраски срезов была значительно ниже. При более продолжительном настаивании интенсивность окраски ядер клеток снижалась, а цитоплазмы - увеличивалась, что свидетельствовало об ухудшении тинкториальных свойств красителя. Для экстрактов цветков экспериментальные периоды настаивания составляли 1-3 ч, день, неделю, 2 недели, месяц, 5 месяцев. Значительного влияния на окраску срезов длительность настаивания в этом случае не имела. Интенсивность окрашивания срезов в большей степени зависела от окраски самих цветков и периода цветения. Для цветков донника лекарственного и бархатцев распростертых оптимальное время настаивания - от недели до месяца, для экстракции возможно использование $70 \%$ спирта.

Схема получения экстрактов:

1. Взвешивание, измельчение (свежие плоды и цветки разминают в ступке).

2. Подготовка экстрагента - $90 \%$ спирта, смешивание измельченного сырья с экстрагентом в соотношении 1,8-2:1 для плодов бузины и $1: 1,5-2$ для цветков донника и бархатцев.

3. Настаивание при комнатной температуре (для плодов бузины 10-17 дней, для цветков донника и бархатцев от недели до месяца).

4. Очистка путем фильтрации через многослойную марлю.

Введение после нескольких дней настаивания 15-минутного нагревания спиртовых экстрактов на водяной бане при температуре $85-90{ }^{\circ} \mathrm{C}$ [12] в ряде случаев приводило к большей интенсивности окраски гистологических срезов. Однако при соблюдении оптимального соотношения сырье : экстрагент и сроков настаивания возможно исключение этой стадии из схемы получения красителя.

Из плодов бузины черной был получен непрозрачный темно-красный раствор (pH соответствует индикатору 0-1), который можно хранить в темном месте в течение длительного времени (минимальный срок 
6 месяцев). Непосредственно перед окрашиванием добавляют медный купорос из расчета 2-2,5 г на 50 мл раствора и тщательно размешивают. Цвет раствора немного темнеет, рН практически не меняется. В полученный краситель помещают депарафинированные срезы на 20-30 мин. После красителя срезы помещают в 70\% раствор спирта на 3-5 с. Здесь происходит «дифференцировка» и удаление избытка красителя. Затем срезы переносят в 96\% спирты (×2) и ксилол (×2) на 35-45 с в каждый и заключают под покровные стекла. Красящий раствор может быть использован повторно на протяжении как минимум 4 недель.

Темный желто-зеленый раствор был получен из цветков донника лекарственного (рН соответствует индикатору 6) и темно-красный (бордовый) - из цветков бархатцев распростертых (рН 5-6). Полученные растворы можно хранить в темном месте в течение длительного времени (минимальный срок - 8 месяцев) при комнатной температуре. Непосредственно перед окрашиванием добавляют железный купорос из расчета 2-2,5 г на 50 мл раствора и тщательно размешивают. При этом раствор становится темно-зеленым, непрозрачным и густым. Значение рН увеличивается до 8 для настоя из бархатцев и практически не меняется для раствора на основе донника. В полученный краситель помещают депарафинированные гистологические срезы на 20-30 мин. При добавлении меньшего количества железного купороса (1,5 г на 50 мл раствора) интенсивность окрашивания ниже и время экспозиции может быть увеличено. Не растворившиеся кристаллы купороса на дне раствора выбрасывать не нужно. Методика окрашивания описана выше. Красящий раствор хранят в темном месте при комнатной температуре. Возможно его повторное использование на протяжении как минимум 2-3 недель. Важным достоинством полученных красителей является возможность их сочетанного использования с ядерными красителями растительного происхождения. В этом случае сначала срезы помещают на 20 мин в раствор красителя, окрашивающего ядра клеток, затем срезы быстро споласкивают в 70\% спирте и переносят в растворы красителей на основе донника лекарственного или бархатцев еще на 10 мин. Для более интенсивного окрашивания ядер рекомендуется более длительная экспозиция в растворе ядерного красителя и менее продолжительная - в цитоплазматических красителях.

Наличие красящих флавоноидных пигментов в экстрактах подтверждено качественными реакциями. В таблице электронного приложения представлены результаты изменения цвета экстрактов при добавлении растворов аммиака, натрия гидрокарбоната и в присутствии борной и лимонной кислоты.

\section{Результаты и обсуждение}

При использовании красителя на основе бузины черной наблюдается отчетливое и специфичное окрашивание ядер и базофильных структур цитоплазмы клеток различных органов в темно-красный цвет. Очень хорошо определяется цитоархитектоника структур головного мозга (рис. В), великолепно дифференцируются различные гистологические структуры во всех органах (рис. А-Е). В связи с этим возможно моноокрашивание гистологических срезов красителем на основе бузины черной без комбинирования с другими красителями. Полученные препараты прекрасно подходят для последующих морфометрических исследований. Окрашивание стойкое, срезы не обесцвечиваются. С практической точки зрения важно, что красящий раствор многоразовый. Его можно повторно использовать на протяжении как минимум 4 недель. Полученный краситель может заменить дорогой (1 600000 руб. за 1 кг) импортный краситель крезиловый фиолетовый, традиционно использующийся для изучения нервной ткани. Результаты сравнительного окрашивания срезов мозжечка крысы крезиловым фиолетовым (А) и новым красителем на основе бузины черной (Б) представлены на рисунке 1 электронного приложения. Четкость идентификации нейронов, их ядер и глиальных клеток и отсутствие фона позволяют говорить о превосходстве нового красителя.

На основе данных о химическом составе плодов бузины черной [13] уместно предположить, что красящим пигментом полученного красителя является антоцианин самбуцин. При гидролизе он распадается на цианидин (безуглеводный остаток или агликон), глюкозу и рамнозу [13]. В настоящей работе наличие антоцианов было подтверждено качественными реакциями с растворами аммиака и гидрокарбоната натрия (электронное приложение, табл.). Нагревание спиртовой настойки в предлагаемой схеме экстракции способствовало отделению агликона от углеводных составляющих и увеличивало интенсивность окраски получаемого экстракта. Выбор этилового спирта в качестве экстрагента в настоящей работе обоснован несколькими причинами. Известно, что агликон цианидин, отвечающий за красильные свойства, растворим в спирте. Более того, при экстрагировании спиртом наблюдается самое высокое содержание антоциановых соединений, обеспечивается их большая стабильность и сохранность [14]. Использование растворов этанола меньшей концентрации, например 70\% спирта, для экстрагирования антоцианов плодов бузины черной, содержащих 
гетероциклический атом кислорода, проявляющий основные свойства в кислой среде, приведет к значительному увеличению концентрации воды в экстракте. Известно, что в водной среде антоцианидины легко гидратируются, а оксониевый кислород меняет заряд с положительного на отрицательный. Это приводит сначала к изменению цвета раствора, а затем к исчезновению окраски в связи с образованием бесцветных форм желтых халконов. По этой причине в наших экспериментах при использовании горячей воды в качестве экстрагента интенсивность окрашивания гистологических срезов была слабой, а красящий раствор не мог быть использован повторно. Медный купорос в составе красителя выступает в роли «протравы», содержащей металлыкомплексообразователи (медь), которые служат акцепторами для гетероциклического атома кислорода, входящего в состав хроменилиевого цикла антоцианов [15]. В результате образующихся химических связей происходит закрепление красителя в гистологических препаратах. От способов получения пищевых красителей на основе плодов бузины черной $[7,8]$ данный метод отличается способом экстракции и характером экстрагентов. Для пищевых красителей это горячая вода, подкисленная лимонной кислотой [7], горячий (40-45 $\left.{ }^{\circ} \mathrm{C}\right)$ водно-спиртовой раствор, подкисленный лимонной кислотой, или обработка кислотно-спиртовой смесью после предварительного сбраживания и сгущения сока [8].
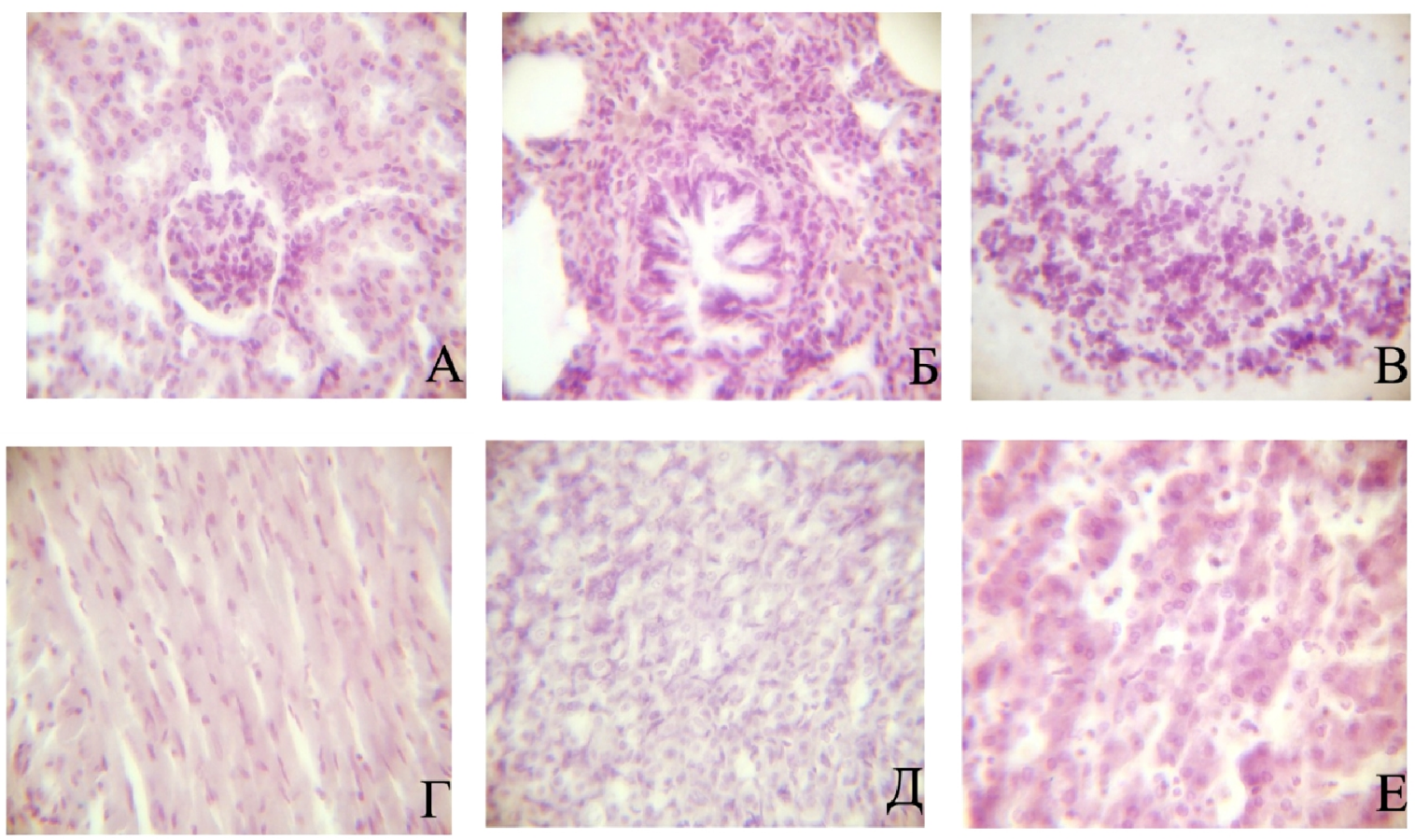

Окрашивание новым красителем на основе экстракта бузины черной срезов различных органов: А - почек, Б - легких, В - мозжечка, Г - сердца, Д - желудка, Е - печени. Ув. ×400.

При использовании красителей на основе экстрактов бархатцев распростертых (электронное приложение, рис. 2) и донника лекарственного (электронное приложение, рис. 3) наблюдается преимущественное окрашивание цитоплазмы клеток различных органов в темно-желтый или зеленый цвет. При сочетанном использовании с красителем ядерного типа на основе бузины черной отчетливо визуализируются ядра клеток с особенностями структуры хроматина и хорошо визуализируются мембраны клеток. Соединительнотканные прослойки и кровь в синусоидных капиллярах печени (электронное приложение, рис. 2Д, Е, рис. 3В, Г) окрашены новыми красителями в темно-желтый цвет. Таким образом, красители на основе экстрактов бархатцев и донника лекарственного позволяют дифференцировать различные тканевые элементы. Полученные с их помощью препараты подходят для обзорных целей и последующих морфометрических исследований. И в этом случае обесцвечивания срезов при хранении не происходит. Результаты сравнительного окрашивания срезов печени крысы рутинным методом гематоксилин + эозин (А) и новыми красителями (экстракт бузины черной + экстракт бархатцев) (Б) представлены на рисунке 4 в электронном приложении. Новые методики не только не уступают старым, но и позволяют более четко дифференцировать мембраны клеток, что особенно ценно при морфометрическом анализе. 
Имеющиеся в литературе сведения о химическом составе цветков бархатцев распростертых и донника лекарственного позволяют утверждать, что их красящими пигментами являются флавоноиды [2, 6]. Эта группа соединений растворяется в спиртах и хорошо в них экстрагируется. Немаловажно, что в процессе получения гистологических красителей этиловый спирт не нужно извлекать из красящего раствора. Более того, он выступает в роли консерванта и значительно увеличивает длительность хранения. Согласно исследованиям $[4,6]$, основными флавоноидами цветков бархатцев распростертых являются флавоны и флавонолы: патулетин, патулитрин, рутин, робинин, дигидрокверцетин, кверцетин, гиперозид, виценин и лютеолин-7-гликозид. По данным В.И. Дейнека с соавт. [16] в цветках бархатцев также содержатся антоцианы, которые могут образовывать комплексы с флавонами и флавонолами посредством водородных связей между гидроксильными группами. В траве донника лекарственного методом ВЭЖХ установлено, что основным флавоноидом является рутин (флавонол) [2]. Кверцетин, лютеолин и робинин содержатся в незначительном количестве. Наличие флавоновых и флавоноловых пигментов в экстрактах донника и бархатцев в настоящей работе было подтверждено качественными реакциями. В присутствии аммиака, натрия гидрокарбоната, борной и лимонной кислот наблюдалось появление желтого окрашивания. Изменение цвета экстрактов после добавления солей железа на темно-зеленый указывает на наличие высокого содержания флавоноидов с двумя гидроксилами в кольце В, т.е. рутина, кверцетина, лютеолина. Красильные свойства кверцетина (флавонол) и лютеолина (флавон) известны давно. На их основе разработаны красители для шелковых и шерстяных тканей. В настоящей работе из природных флавоновых и флавоноловых пигментов получены красители для гистологических целей. Наличие в структуре указанных пигментов фенольных ОН-групп объясняет слабокислые свойства новых цитоплазматических красителей. Механизм окрашивания заключается в образовании прочных комплексов между ионами железа и фенольными гидроксильными и карбонильными группами указанных флавоноидов.

\section{Bblводbl}

Таким образом, в настоящей работе получен основной гистологический краситель на основе плодов бузины черной, который можно рекомендовать для широкого использования в гистологической практике с целью окрашивания ядер клеток и изучения цитоархитектоники головного и спинного мозга. На основе флавоновых и флавоноловых соединений цветков бархатцев распростертых и донника лекарственного получены цитоплазматические красители, которые можно использовать совместно с ядерными красителями растительного происхождения. К достоинствам новых красителей можно отнести доступность и широкое распространение растительного сырья, использование нетоксичных и недорогих ингредиентов, простоту приготовления растворов и возможность их длительного хранения и повторного использования.

\section{Список литературы}

1. Милованова 3.П., Лысенко Л.В. Общие принципы и методы окрашивания гистологических препаратов // Микроскопическая техника : руководство для врачей и лаборантов / под ред. Д.С. Саркисова и Ю.Л. Перова. М., 1996. 544 c.

2. Бубенчикова В.Н., Дроздова И.Л. Изучение состава фенольных соединений донника лекарственного методом ВЭЖХ // Химико-фармацевтический журнал. 2004. Т. 38. № 4. С. 24-25.

3. Федосеева Л.М., Харлампович Т.А. Изучение некоторых водорастворимых соединений донника лекарственного травы (Melilotus officinalis L.) // Химия растительного сырья. 2013. № 2. С. 153-157.

4. Папаяни О.И., Духанина И.В., Сергеева Е.О. Изучение химического состава и антимикробной активности сухого экстракта из цветков бархатцев распростертых (Tagetes Patula L.) // Известия Самарского научного центра РАН. 2012. Т. 14. № 5. С. 742-744.

5. Ефремов А.А., Зыкова И.Д., Целуковская М.М. Компонентный состав биологически активных веществ донника лекарственного (желтого) // Химия растительного сырья. 2012. № 3. С. 111-114.

6. Подгорная Ж.В. Исследование цветков бархатцев распростертых (Tagetes Patula L.) с целью получения биологически активных веществ : автореф. дисс. ... канд. фарм. наук. Пятигорск, 2008. 24 с.

7. Харламова О.А. Натуральные пищевые красители. М., 1979. 190 с.

8. Патент № 2287547 (РФ). Способ получения красного пищевого красителя из растительного сырья / М.С. Мурадов, Т.Н. Даудова, Л.А. Рамазанова / 2006.

9. Hou D-X., Fujii M., Terahara N., Yoshimoto M. Molecular mechanisms behind the chemopreventive effects of anthocyanidins // J. Biomed. Biotech. 2004. Vol. 5. Pp. 321-325.

10. Mena P., Dominguez-Perles R., Girones-Vilaplana A., Baenas N., Garcia-Viguera C., Villano D. Flavan-3-ols, anthocyanins, and inflammation // IUBMB Life. 2014. Vol. 66. N 11. Pp. 745-758. 
11. Wallace T.C. Anthocyanins in cardiovascular disease // Adv. Nutr. 2011. Vol. 2. Pp. 1-7.

12. Егорова А.В., Куркин В.А., Каримова А.М. Изучение возможностей комплексного использования плодов черной смородины (Ribes nigrum L.) // Известия Самарского научного центра РАН. 2012. Т. 14. № 1. С. 2215-2217.

13. Церевитинов Ф.В. Химия и товароведение свежих плодов и овощей. М., 1949. Т. 1. 619 с.

14. Саввин П.Н., Комарова Е.В., Болотов В.М., Шичкина Е.С. Исследование натуральных каротиноидноантоциановых красителей // Химия растительного сырья. 2010. № 4. С. 135-138.

15. Чупахина Г.Н., Масленников П.В., Скрыпник Л.Н. Природные антиоксиданты (экологический аспект). Калининград, 2011. $111 \mathrm{c.}$

16. Дейнека В.И., Третьяков М.Ю., Дейнека Л.А., Сорокопудов В.Н. Некоторые особенности накопления пигментов в цветках Tagetes SP // Научные ведомости Белгородского государственного университета. Серия: Естественные науки. 2007. Т. 5. № 5. С. 123-129.

Поступило в редакциию 11 февраля 2016 г.

После переработки 19 декабря 2016 г. 
Ishunina T.A. *, Boeva S.G. DEVELOPMENT OF TECHNOLOGY FOR THE PREPARATION AND USE OF HISTOLOGICAL DYES ON THE BASIS OF EXTRACTS OF BLACK ELDERBERRY AND THE MARIGOLD AND MELILOT FLOWERS.

Kursk State Medical University, ul. Karla Marxa, 3, Kursk, 305041 (Russia), e-mail: ishunina@gmail.com.

On the basis of ethanol extracts of fruits of black elderberry (Sambucus nigra L.), marigold (Tagetes patula L.) and melilot (Melilotus officinalis L.) flowers new histological dyes were obtained. Anthocyanins of elderberry fruits that contain a positively charged oxygen provide basic properties of the corresponding dye, which selectively stains the nuclei and the basophilic structures of the cytoplasm. Donor-acceptor bonds between the heterocyclic oxygen atom of anthocyanins and a metalcomplexing agent (copper) in the copper sulfate play an important role in the staining mechanism. Flavonoids of the marigold and melilot flowers, by contrast, show weakly acidic properties due to the presence of hydroxyl groups and predominantly stain the cytoplasm and the cell membrane. The chemical mechanism of the staining can be explained by the formation of stable complexes between ferric ions and phenolic hydroxyl and carbonyl groups of flavonoids. In this regard, the new stains should be considered as mordant dyes. Their advantages include the availability and wide distribution of vegetable raw materials, usage of nontoxic and affordable ingredients, easy preparation of solutions and the possibility of their long-term storage and reuse. Moreover, the nuclear dye from black elderberry can be used for combined histological staining with cytoplasmic dyes based on the marigold and melilot flowers.

Keywords: histological dyes of vegetable origin, nuclear and cytoplasmic dyes, the fruits of black elderberry, flowers of marigold, the flowers of Melilotus officinalis, flavonoids, anthocyanins.

\section{References}

1. Milovanova Z.P., Lysenko L.V. Mikroskopicheskaia tekhnika. Rukovodstvo dlia vrachei i laborantov [Microscopic technique. Manual for doctors and laboratory technicians], ed. D.S. Sarkisov, Iu.L. Perov. Moscow, 1996, 544 p. (in Russ.).

2. Bubenchikova V.N., Drozdova I.L. Khimiko-farmatsevticheskii zhurnal, 2004, vol. 38, no. 4, pp. 24-25. (in Russ.).

3. Fedoseeva L.M., Kharlampovich T.A. Khimiia rastitel'nogo syr'ia, 2013, no. 2, pp. 153-157. (in Russ.).

4. Papaiani O.I., Dukhanina I.V., Sergeeva E.O. Izvestiia Samarskogo Nauchnogo tsentra RAN, 2012, vol. 14, no. 5, pp. 742-744. (in Russ.).

5. Efremov A.A., Zykova I.D., Tselukovskaia M.M. Khimiia rastitel'nogo syr'ia, 2012, no. 3, pp. 111-114. (in Russ.).

6. Podgornaia Zh.V. Issledovanie tsvetkov barkhattsev rasprostertykh (Tagetes Patula L.) s tsel'iu polucheniia biologicheski aktivnykh veshchestv: avtoref. diss. ... kand. farm. nauk. [Research of flowers of marigolds spread (Tagetes Patula L.) with the purpose of obtaining biologically active substances: the author's abstract. Diss. Candidate of Pharmaceutical Sciences]. Piatigorsk, 2008, 24 p. (in Russ.).

7. Kharlamova O.A. Natural'nye pishchevye krasiteli. [Natural food colorings]. Moscow, 1979, 190 p. (in Russ.).

8. Patent 2287547 (RU). 2006. (in Russ.).

9. Hou D-X., Fujii M., Terahara N., Yoshimoto M. J. Biomed. Biotech., 2004, vol. 5, pp. 321-325.

10. Mena P., Dominguez-Perles R., Girones-Vilaplana A., Baenas N., Garcia-Viguera C., Villano D. IUBMB Life, 2014, vol. 66 , no. 11 , pp. $745-758$.

11. Wallace T.C. Adv. Nutr., 2011, vol. 2, pp. 1-7.

12. Egorova A.V., Kurkin V.A., Karimova A.M. Izvestiia Samarskogo Nauchnogo tsentra RAN, 2012, vol. 14, no. 1, pp. 2215-2217. (in Russ.).

13. Tserevitinov F.V. Khimiia i tovarovedenie svezhikh plodov $i$ ovoshchei. [Chemistry and Commodity Research of Fresh Fruits and Vegetables]. Moscow, 1949, vol. 1, 619 p. (in Russ.).

14. Savvin P.N., Komarova E.V., Bolotov V.M., Shichkina E.S. Khimiia rastitel'nogo syr'ia, 2010, no. 4, pp. $135-138$. (in Russ.).

15. Chupakhina G.N., Maslennikov P.V., Skrypnik L.N. Prirodnye antioksidanty (ekologicheskii aspekt). [Natural antioxidants (ecological aspect)]. Kaliningrad, 2011, 111 p. (in Russ.).

16. Deineka V.I., Tret'iakov M.Iu., Deineka L.A., Sorokopudov V.N. Nauchnye vedomosti Belgorodskogo gosudarstvennogo universiteta. Seriia: Estestvennye nauki, 2007, vol. 5, no. 5, pp. 123-129. (in Russ.).

Received February 11, 2016

Revised December 19, 2016

\footnotetext{
* Corresponding author.
} 
